Revista Iberoamericana, Vol. LXX, Núm. 207, Abril-Junio 2004, 419-430

\title{
NOTICIA DE UN SECUESTRO DE GABRIEL GARCÍA MÁRQUEZ: ENTRE EL CUENTO POPULAR Y EL REPORTAJE
}

\author{
POR \\ Luis C. Cano \\ University of Tennessee
}

Una de las formas más populares del relato folclórico occidental sigue el heroico recorrido de un individuo que, por circunstancias que escapan a su control, resulta comprometido en una confrontación con las fuerzas del mal. En la más conocida de las variaciones, una hermosa dama, representación de todos los principios de nobleza y virtud, es secuestrada por una perversa criatura que ha creado un imperio de horror. Esta acción desencadena la cólera del héroe quien, apoyado en su valor, astucia y generosidad, afronta variadas pruebas e innumerables peligros, los cuales culminan con el rescate de la dama y la derrota del malvado. ${ }^{1}$ Tradicionalmente identificada con los relatos populares y los cuentos infantiles, esta estructura reaparece, de forma reiterada, en la literatura y el cine de aventuras. Por razones que dependen de las siempre ambiguas conceptualizaciones de lo culto y lo popular, su presencia es menos frecuente en la literatura canónica. Una notable excepción es la novela Noticia de un secuestro (1996), del escritor colombiano Gabriel García Márquez, la cual apoya sus aspiraciones periodísticas en la estructura tradicional del relato folclórico que ha sido descrito al comienzo de este ensayo.

En 1989, varias importantes personalidades colombianas, en su mayor parte periodistas, fueron secuestrados por un grupo autodenominado "Los extraditables”. El propósito del secuestro era ejercer presión sobre la política de extradición de narcotraficantes a los Estados Unidos. Después de varios meses de angustiosa incertidumbre, durante los cuales son asesinadas dos de las mujeres secuestradas, el caso culmina con la liberación de los otros prisioneros y con la entrega de Pablo Escobar, cabeza visible de los extraditables, a las autoridades colombianas. En el epílogo de la obra los lectores se enteran de que, tiempo después, el líder del más famoso cartel de la droga escapa de la cárcel para, posteriormente, ser asesinado. El hilo de la narración sigue las vicisitudes de la periodista Maruja Pachón y los esfuerzos de su esposo, Alberto Villamizar, para lograr su liberación, a la vez que entreteje observaciones sobre la historia del narcotráfico, la presión que éste ejerce sobre el gobierno y los devastadores efectos de la confrontación en la sociedad colombiana.

Como se sugiere en los párrafos introductorios de este ensayo, el relato popular de la tradición folclórica occidental (específicamente la europea) es la estructura subyacente

\footnotetext{
${ }^{1}$ Para un catálogo de argumentos sobre el tema del rescate de la princesa referirse al capítulo II de la obra Los tipos del cuento folklórico, de Antti Aarne y Stith Thompson.
} 
de la obra, que la sostiene estructuralmente y que le aporta el tono narrativo al reportaje. Una vez comenzada la lectura nos hallamos frente a una búsqueda emprendida por un héroe (Villamizar) para rescatar a la heroína (Maruja) de las garras de un monstruo (narcotraficantes), todo ello situado en el contexto de la tradicional lucha entre el bien (la justicia) y el mal (crimen organizado). Se presentan también otras características del relato folclórico como la soledad de la lucha y el encuentro de ayudantes generosos que posibilitan un final exitoso. Coherente con esta estructura, observamos un gradual enaltecimiento del héroe y de la heroína, resultado del sufrimiento y de la superación de ciertas pruebas que aparecen a lo largo del recorrido. ${ }^{2}$

Una inquietud obvia se desprende de la identificación de este modelo escritural en Noticia de un secuestro: ¿por qué adopta el escritor colombiano una estructura narrativa tradicionalmente asociada con lo irreal y, en consecuencia, aparentemente contradictoria con el propósito periodístico proclamado en las “Gratitudes”, especie de prólogo de la obra? Parece evidente que la elección del relato folclórico como base de la narración en Noticia de un secuestro trasciende la necesidad primaria de recurrir a un andamiaje narrativo para presentar los resultados de una investigación periodística. Más allá de esta motivación, la decisión artística de García Márquez constituye un minucioso análisis de las relaciones entre la literatura y el periodismo, el cual disecciona los principios organizativos de ambos discursos, la influencia recíproca que ejercen al interior de la obra y, más importante aún, la responsabilidad social que los dos géneros confrontan. Como resultado, la obra propone la inesperada integración de los dos discursos mediatizada por las inquietudes éticas que comparten.

En casi todas las entrevistas relacionadas con la publicación de Noticia de un secuestro, García Márquez ha insistido en la importancia que le asignó a la estructura de la novela durante el proceso de escritura. En particular, enfatiza el hecho de que ésta se organiza a partir de la oposición afuera (capítulos impares)-adentro (capítulos pares). Interrogado por Luis Cañón, del periódico El País de Cali, Colombia, García Márquez responde:

[L]a idea original fue: los secuestrados en los capítulos impares ... y en los pares, lo que está sucediendo afuera. Para dentro. Para fuera. Cuando me di cuenta que aumentaban los protagonistas, se mantiene así: los que estaban secuestrados estaban de todas maneras en los impares y los que estaban afuera en los pares. Tenía que ser así, parejo, adentro y afuera. (El País edición electrónica)

La conexión entre la estructura de una obra y el referente extratextual, enfatizada por García Márquez tanto en sus entrevistas como en la composición general de Noticia de un secuestro, recupera una problemática inherente al relato popular, ya detectada años atrás por los estudios estructuralistas: el intento de organización de las conductas humanas en

${ }^{2}$ Géza Róheim en Fire in the Dragon, indica algunos rasgos de este tipo de narración: la humanidad de los personajes (en oposición a la divinidad o semidivinidad), la ausencia general de nominación, la indeterminación espacio-temporal, y el hecho de que el relato popular es una ficción pura, sin abiertas pretenciones de significar algo diferente (30-31). Para ampliación de estos rasgos ver las obras de Workman, Róheim y Propp. 
un modelo previamente orientado hacia un objetivo preestablecido. En el núcleo de un relato popular se expresa la idea de que existe una lógica universal la cual permite ordenar las acciones humanas en un devenir organizado (Bremond 108-109). De acuerdo con esta concepción, más allá de la posibilidad de una combinación libre de los elementos que constituyen la narración básica, de los hechos cronológicamente organizados en el relato, hay una lógica intemporal que los unifica y confiere sentido.

La situación que se pone en juego es la misma que Roland Barthes describe en su "Introducción al análisis estructural de los relatos”: "La realidad de una secuencia no está en la sucesión natural de las acciones que la componen, sino en la lógica que en ellas se expone, se arriesga y se cumple” (43). En otras palabras, lo que explica el énfasis en la estructura de Noticia de un secuestro es la aspiración a que la organización misma del material constituya un modelo interpretativo que sobrepase la inmediatez de los acontecimientos y se convierta en una reflexión sobre conceptos tales como ética, ficción y periodismo. No obstante, la adopción del formato del relato folclórico parece chocar con algunas de las cualidades propias del discurso periodístico, como la pretensión de capturar el instante, el énfasis en la novedad y la importancia de la percepción sobre lo cognitivo. En las formas en que la obra resuelve esta tensión concentraremos nuestra atención en las próximas páginas.

La presencia del género periodístico como componente central de la narración es bastante explícita. Desde el título se observa que el texto aparece como una "noticia”. En una entrevista concedida a Roberto Pombo, previa a la publicación de su obra, García Márquez señala el hecho de que el título sitúa Noticia de un secuestro al lado de otros dos “reportajes” en su producción escritural: Relato de un náufrago y Crónica de una muerte anunciada:

He estado pensando en el título. Siempre tuve Noticia de un secuestro, porque necesitaba una palabra periodística. Ya tengo Relato de un náufrago y Crónica de una muerte anunciada, me faltaba una noticia, porque he llegado a la conclusión de que el reportaje no es más que la noticia completa. (Pombo 455)

Muchos otros elementos señalan hacia las relaciones de la obra con el periodismo: nueve de los diez secuestrados están vinculados a los medios de comunicación; la inclusión de fechas, nombres e informaciones exactas verificables extratextualmente, proceden de un proceso de investigación reporteril descrito por el autor en las “Gratitudes”. Adicionalmente, hay innumerables referencias a la función que la prensa escrita, la radio y la televisión desempeñaron durante el largo período de confrontación entre el Gobierno colombiano y los Extraditables, y a la forma como estos medios fueron utilizados como vehículo para transmitir mensajes a los secuestrados.

Al lado de estos aspectos temáticos, se pueden reconocer ciertos rasgos formales que señalan hacia el texto noticioso: la tendencia a la ocultación del "yo" narrativo; la presentación de la información extratextual y la importancia de las fuentes como una proclama de la veracidad del relato; el énfasis en los detalles; la exhaustividad que promete aportar el máximo de información; la retórica del periodismo sensacionalista expresada en 
la profusión adjetival que aporta cierto tono apocalíptico; finalmente, el discurso ético, aspecto sobre el cual volveremos con mayor detenimiento un poco más adelante.

El contraste entre la base estructural de la obra (relato popular) y el material y la retórica de su composición (discurso periodístico), establece una tensión entre la concepción del tiempo como un devenir sujeto al cambio y caracterizado por la fugacidad -rasgo inherente al periodismo- y la concepción de un tiempo sólido e inmutable, propia de la rígida estructura del cuento popular tradicional. El relato folclórico presenta una clara orientación hacia el pasado; su relación con el presente es una relación de autoridad en la que el pasado, conmemorado en la tradición y el ritual, legitimiza el momento actual (Workman 29). La escritura periodística se concentra menos en la trama y más en el hecho, en el instante; es cierto que hay una descripción de sucesos en su secuencia temporal, pero tal descripción no es predominantemente causal; en general las conexiones entre causa y efecto se le dejan al lector o se presentan a largo plazo (González-Pérez, Journalism...). En conclusión, mientras que el discurso periodístico constituye en sí mismo una especie de exaltación de la temporalidad (todo en el texto noticioso remite de una u otra forma a la problemática temporal), la concepción que se desprende del relato popular tradicional es lo que podríamos denominar, utilizando el lenguaje borgiano, una apoteosis de la causalidad: un orden en el cual cada elemento constituye una expresión de la totalidad.

La lógica determinista, propia del relato folclórico, encuentra una realización particular en el fenómeno de las premoniciones. Para los lectores familiarizados con la producción literaria de Gabriel García Márquez la presencia de este mecanismo escritural en Noticia de un secuestro resulta menos extraña. Al fin y al cabo, la percepción inexplicable de hechos que aún no han ocurrido o los cuales se desarrollan en el preciso momento de la experiencia extranatural, constituye una de las constantes de su producción narrativa. De hecho, este procedimiento es uno de los motivos centrales de Crónica de una muerte anunciada. Lo que sí parece un poco incongruente es encontrarlas en una obra con claras pretenciones de reportaje periodístico. Podría pensarse, en principio, que la conexión con el relato popular justificaría su inclusión debido a la sensación de irrealidad con la que ambos se asocian. Sin embargo, es evidente que ni la presencia del relato folclórico, ni la de los presagios, despojan a la obra de su poder evocador de la realidad extratextual. Al contrario, las premoniciones de Maruja, Nydia, Martha Lupe, Diana, la misma Marina, y la certeza interpretativa de la vidente, le otorgan, paradójicamente, una fuerte sensación de realismo al relato. El enfrentamiento con lo ineludible hace más frágiles a las víctimas, y la esperanza de un "final feliz" que algunas de las premoniciones auguran, genera la ilusión de un vínculo emocional más íntimo entre los personajes de la obra y los receptores de la misma.

La función de la premonición en Noticia de un secuestro (y en general en las obras de García Márquez) trasciende el nivel argumental para constituirse en manifestación de una figura retórica mayor: la figura analógica de la correspondencia. ${ }^{3}$ Para una visión del

\footnotetext{
${ }^{3}$ El empleo de este término sigue la propuesta de Paul Gillen, basada en la cosmología del místico Emanuel Swedenborg: todo en el cosmos se corresponde, el todo y las partes, y esta correspondencia requiere de un proceso de interpretación. El concepto es afín a la idea de proceso analógico que Octavio Paz propone en Los hijos del limo, la cual explora la reflexión de Swedenborg en la obra de Baudelaire.
} 
mundo regida por el concepto analógico, el universo es una totalidad expresiva en la que el todo se manifiesta en sus partes. Uno de los efectos de la actitud analógica es la ruptura con la percepción de lo diferente, como bien lo expresa Paul Gillen: "If everything corresponds with everything else, the literal and metaphorical, the known and the unknown, become one” (411). Octavio Paz, por su parte, añade que la analogía, como “ciencia de las correspondencias” (109) trae como consecuencia la atracción de opuestos; es la manifestación del tiempo cíclico y mítico. Aún más, la analogía permite ver y leer el universo al mismo tiempo que se constituye en una fuente de conocimiento y de acción (86). Tanto la reflexion de Paz como la de Gillen coinciden en señalar la actitud totalizadora de la analogía, rasgo que explica la inclinación del autor colombiano a hacerla un motivo recurrente dentro de su narrativa.

Temáticamente, las premoniciones en Noticia de un secuestro apuntan hacia la ruptura de distancias (literal y metafóricamente hablando) en la organización estructural de los capítulos. Ante la intención “realista” señalada por García Márquez al describir el desconocimiento de los personajes de lo que ocurre "afuera” o “adentro”, la premonición aparece como un mecanismo de trascendencia de los ámbitos espacial y temporal; la relación de Nydia y Diana “como un milagro de clarividencia” (144), las prefiguraciones de la vidente y las repentinas certezas de que algo ha sucedido en el instante mismo de su realización, son una forma de acceder a una información imposible de alcanzar por métodos naturales. Las correspondencias como mecanismo narrativo rompen lo monolítico y estático de las categorías puras para darle dinamismo al texto; su cualidad "conectora” permite deshacer las barreras que separan las dualidades argumentales, las cuales se concretan, finalmente, en la problemática moral que engloba la narración: la confrontación entre las fuerzas del bien y del mal.

La relación entre el relato popular y el periodismo en Noticia de un secuestro se establece a partir de la preocupación de carácter ético que ambas modalidades proponen cuando se sitúan en un contexto literario. ${ }^{4}$ Aníbal González-Pérez, en su obra Journalism and the Development of Spanish American Narrative, propone la hipótesis de que en la ficción latinoamericana “the use of journalistic discourse, or journalism's presence as a motif, is always linked to ethical or moral considerations” (109), comentario que se encuentra ampliamente sustentado en las repetidas observaciones que Noticia de un secuestro incluye en cuanto a la función de los medios de comunicación en la delicada situación que constituye el núcleo narrativo del relato.

El relato popular, por su parte, presenta varios niveles de asociación. En primer lugar, dirige la atención hacia algunas problemáticas específicas de la composición de un texto literario (relaciones entre fábula y discurso, focalización, voz narrativa, concepción de la temporalidad, etc.). En segundo lugar, más significativo para este estudio, señala la

\footnotetext{
${ }^{4}$ Paul de Man considera la ética como un discurso y la define como "the structural interference of two distinct value systems” (206), concepto básico que Aníbal González-Pérez adopta en su estudio Journalism and the Development of Spanish American Narrative. Geoffrey Harpham, por su parte, rechaza la idea de ética como un tipo de discurso que orienta a sus usuarios hacia o contra un sistema de valores; en su lugar, propone que es la elección misma del lenguaje por parte de los individuos la que implica las decisiones de tipo ético.
} 
función social tradicional del cuento folclórico como instrumento de reflexión ética. ${ }^{5}$ En él se concentran, en su más puro estado, lo que Geoffrey Harpham denomina “utilidades éticas” de la literatura: articulación de propósitos, orientación para entender las situaciones humanas, moralización de la acción mediante la evaluación de su resultado, presentación de modelos de comportamiento, ofrecimiento de un espacio para que el receptor reconozca la norma moral y las relaciones que se establecen entre comunidad e individuo, fijación del pasado y moldeamiento de la unidad deseable en la vida social (165-66).

Esta es precisamente la línea adoptada por García Márquez al momento de estructurar su narración, una decisión artística que explica la sorprendente incorporación de las categorías de bondad y maldad en una obra que abiertamente se proclama como un reportaje. En una de las reflexiones acerca de la situación por la cual atravesaba el Gobierno colombiano, el narrador expresa:

[E]l problema de fondo, tanto para el gobierno como para el narcotráfico y las guerrillas, era que mientras Colombia no tuviera un sistema de justicia eficiente era casi imposible articular una política de paz que colocara al Estado del lado de los buenos, y dejara del lado de los malos a los delincuentes de cualquier color. (162)

El recurso de las oposiciones irreductibles concretado en la oposición entre el bien y el mal, aparece reiterado en diferentes niveles de narración: la división de la obra en capítulos pares (situados afuera y llenos de acción) y capítulos impares (adentroestatismo); la presencia de dualidades argumentales (Pablo Escobar-César Gaviria; secuestradores-secuestrados; Extraditables-Notables) en las que uno de los términos está definitivamente del "lado de los malos" mientras que el otro se ubica del "lado de los buenos”.

En principio, nos hallamos situados al interior de una concepción maniqueísta del universo en la que cada una de las dualidades que se contraponen representan los principios de bondad y de maldad. Pero esta composición se desgasta internamente mediante el establecimiento de las mencionadas correspondencias, las cuales minan la rigidez categórica que caracteriza el relato popular. A medida que la obra avanza nos encontramos con una serie de puntos de contacto entre los representantes de los dos grupos (El general Maza Márquez y Pablo Escobar comparten las mismas devociones; los secuestradores experimentan situaciones tan degradantes como las que afrontan los secuestrados), o con ciertas caracterizaciones contradictorias con la esencialidad sugerida (el fanatismo religioso de los jóvenes captores en contraposición con la frialdad espiritual de varios de los rehenes) las cuales impulsan una actitud interpretativa crítica en el acto de recepción.

Las figuras que mejor representan este procedimiento de desmantelación de oposiciones son la imagen del santo-loco (Padre García Herreros) y la de Pablo Escobar. Mientras que la imagen del sacerdote no se explora en profundidad, la narración exhibe una fascinación

\footnotetext{
${ }^{5}$ Para un estudio de la forma en la cual los relatos populares devinieron cuentos infantiles con intenciones educativas ver el artículo de John Goldthwaite y la obra de María Tatar, reseñados en la bibliografía.
} 
evidente por el narcotraficante. Este personaje adquiere "algo de sobrenatural” (337) gracias al empleo de la alusión, una técnica similar a la utilizada en los cuentos folclóricos para caracterizar las figuras representativas de la maldad absoluta: una presencia constante, la cual nunca se presenta en la plenitud de su poder, pero cuya amenaza está presente en cada instancia narrativa.

Pero el aspecto más interesante para los propósitos de este ensayo es la seducción que el estilo escritural de Escobar ejerce sobre el narrador. Ya es bastante significativo el hecho de que en dos diferentes apartados de la obra encontremos la misma descripción de la escritura del narcotraficante: "Sus comunicados de estilo ejemplar y cautelas perfectas llegaron a parecerse tanto a la verdad que se confundían con ella” (100 y 208), observación que no sólo señala hacia la instancia de producción del texto, sino que, además, refiere a los procedimientos de recepción e interpretación. La escritura de Pablo Escobar se convierte en emblema de la aspiración por excelencia de la escritura periodística: la búsqueda de un estilo “conciso, directo y sin equívocos” (Noticia 97). Sin embargo, a medida que la narración avanza, se afirma la idea de que tal aspiración es sólo una ilusión y de que toda apariencia de objetividad se construye mediante una cuidadosa manipulación del discurso. La carta que Escobar elabora con pretenciones editorialistas es descrita como un documento “escrito con seriedad y malicia sutil” (283), con lo que la transición de lo pretendidamente neutral a lo maligno concreta la ficcionalidad de la distancia entre lo bueno y lo malo e instituye una noción esencial para el proyecto ético: la asunción de que existe una coincidencia entre bondad y maldad en la que el segundo término es sólo una variación degradada del primero.

En uno de los pasajes más sorprendentes de la obra, el padre García Herreros expresa su opinión acerca de Pablo Escobar:

[García Herreros] pidió ser tolerantes con Escobar. "Si no lo defraudamos, él se vuelve el gran constructor de la paz," decía. Y agregaba sin citar a Rousseau: "Los hombres en su intimidad son buenos todos, aunque algunas circunstancias los vuelven malignos". Y en medio de una maraña de micrófonos apelotonados, dijo sin más reservas: -“Escobar es un hombre bueno". (298)

El hecho de que este comentario haya sido transmitido por todos los medios de comunicación y de que, además, sea expresado por un individuo cuya imagen está en un continuo vaivén entre lo sublime y lo ridículo, entre la santidad y la locura, le confiere una importancia particular. En oposición a la unidimensionalidad de los personajes del cuento folclórico, las figuras de Escobar, de Gaviria y del padre García Herreros se resisten a una categorización definida. Aunque en principio el gobernante y el narcotraficante encarnan los dos polos opuestos de la contradicción moral, en el transcurso de la narración se utilizan las correspondencias para sugerir la existencia de identidades entre ellos: los dos son extremadamente cuidadosos con lo que dicen o escriben, ambos son focos de conjunción de diversos intereses de poder y, además, comparten una profunda preocupación por la exactitud del lenguaje escrito. El estilo escritural de Escobar, por ejemplo, “conciso, directo y sin equívocos" (Noticia 97), aparece muy similar al de Gaviria: "frases breves que lo resumían todo” (241). De esta forma, en una actitud emblemática de la constante 
búsqueda de objetividad a la que se enfrenta el discurso periodístico, la obra de García Márquez intenta eliminar toda certeza textual que permita determinar con exactitud la posición asumida por el narrador del relato en relación a las dos fuerzas en conflicto.

Es importante, ahora, tratar de dilucidar las razones que llevan al narrador a tomar esta ambigua actitud. Una posible manera de abordar esta situación sería canalizar el estudio hacia las exigencias de objetividad que el género periodístico se precia de representar. No obstante, ya es un lugar común la afirmación de que este proyecto, como sucede con los comunicados de Escobar, no es más que el resultado de un ejercicio retórico. Más fructífera es la observación de que la cita sobre la evaluación moral de Escobar, señala la fuente filosófica del concepto de bondad como característica inherente al ser humano: la afirmación de Rousseau de que la naturaleza original del hombre es buena pero que ha sido corrompida por el accidente histórico social.

Los antecedentes de este principio se remontan a la polémica entre la doctrina agustiniana y la secta maniqueísta. En oposición a la creencia maniquea de la existencia del bien y el mal como instancias diferenciadas e irreconciliables, San Agustín propone la idea del mal como privatio boni. En principio sólo existe el bien, y el mal no es más que su desviación (defective good). ${ }^{6}$ Dos consecuencias importantes que se desprenden de este planteamiento son el concepto de libre albedrío (los seres humanos son responsables por sus vicios, en oposición a la concepción maniquea de la no responsabilidad por la inclinación hacia el pecado) y la confianza absoluta en la existencia de una sociedad justa dirigida por un gobernante potencialmente consciente. Aunque posteriormente San Agustín perdió su confianza en la posible existencia de una sociedad y un gobierno perfectos, nunca negó la bondad inherente del ser humano ni reevaluó la concepción del mal como una degradación del bien.

Ahora bien, la adopción de tal estructura, fundamental en la configuración de los hechos como relato, sitúa en una posición delicada un modelo reporteril en busca de la realidad objetiva. Mientras que, por un lado, la dicotomía moral resulta apropiada en la estructura ficcional, por el otro amenaza con demoler la credibilidad del texto, postulado en el que se apoya el programa periodístico. Aún más; la rigidez composicional a la que nos hemos referido previamente en este estudio (capítulos pares vs. capítulos impares; afuera vs. adentro) confronta una dificultad similar: el peligro de extraviar la perspectiva analítica de los vínculos entre las dramáticas experiencias individuales y los procesos sociales que las determinan.

Así, pues, la inserción de la idea de que tanto el bien como el mal comparten el mismo origen, trasciende su valor de referencia anecdótica para constituirse en una afirmación de confianza irreductible en la bondad intrínseca de un pueblo que ha padecido los horrores de la violencia de la droga. Y aún más; el mismo principio le brinda flexibilidad a una estructura cuya rigidez antitética amenaza con deteriorar un proyecto que pretende dar cuenta de las relaciones que se establecen entre el periodismo y la literatura teniendo como objeto central una reflexión de carácter ético. En este contexto, las múltiples correspondencias que se establecen entre las dualidades narrativas constituyen un

\footnotetext{
${ }^{6}$ El artículo "Only something good can be evil" de Frederick Russell, desarrolla un interesante comentario de la polémica entre la secta maniqueísta y San Agustín. Ver también The Free Choice of the Will de San Agustín y el estudio de Gerald Bonner, St. Augustine of Hippo.
} 
mecanismo de enlace que señala la imposibilidad de concebir categorías puras opositivas, especialmente en un universo ficcional que se propone representar un fenómeno extratextual.

Los medios de comunicación se invisten de una función similar a la que desempeñan las correspondencias. Aunque fundamentales como material narrativo en sus funciones primarias de informar y divertir -los secuestradores y los secuestrados mantienen la radio o la televisión encendida todo el día y gran parte de la noche-, es en su carácter de instrumentos de reflexión ética que adquieren una verdadera trascendencia. La obra efectúa una constante evaluación de su participación en las difíciles circunstancias que la nación colombiana ha afrontado en relación con el narcotráfico. Diana y Francisco Santos, desde “dentro" y los directores y periodistas, desde “afuera”, se plantean la necesidad más explícita de una toma de posición por parte de los medios de comunicación, no sólo en la vida nacional, sino en circunstancias de carácter más íntimo. Diana, por ejemplo, se da cuenta que la revista que ella dirige peca por falta de profundidad y de análisis (84); Pacho Santos, fiel a su concepción romántica de la actividad periodística, descubre que "La imparcialidad de los medios ... por la que tanto se luchó y que se estaba abriendo paso, se ha esfumado" (312); las familias de varios de los secuestrados, vinculadas a la televisión y a la prensa escrita, deciden hacer uso de estos medios para establecer una comunicación unidireccional en la que presentan noticias íntimas y mensajes de ánimo que se proponen mantener en alto el espíritu de las víctimas.

En general, la importancia de los medios en la obra está por encima de toda duda: no sólo mantienen informado al público, adelantándose incluso a los investigadores de los organismos de seguridad, sino que se convierten en la única apertura que los secuestrados tienen hacia el mundo exterior, una especie de ventana que les aporta, además de información y entretenimiento, esperanzas. Esta continua exposición a la radio, la prensa y la televisión genera una conciencia de la temporalidad al irrumpir, con su exaltación del presente, en el mundo sin coordenadas de los secuestrados. Su presencia en el espacio cerrado suspende la ilusión de que el tiempo no existe o de que es una categoría inmóvil, y genera una conciencia del fluir del mismo.

Sin embargo, lo positivo de esta presencia se ve afectado por la forma en que los familiares de las víctimas (personalidades con altas posiciones políticas y periodísticas) utilizan los medios de comunicación para proporcionar esperanzas y tranquilidad a sus seres queridos: Alejandra, la hija de Maruja, realiza una serie de programas de televisión que van dirigidos, en general, a todos los secuestrados y, en particular, a su madre; el periódico El Tiempo envía mensajes personales “sin disimulos ni reservas” (258) a su director, Francisco Santos; en la sección deportiva de un noticiero de televisión se incluye el nombre de una medicina para que los secuestradores no se olviden de comprarla.

Esta “desviación” de la función primaria de los medios trae un resultado inesperado que pone en tela de juicio el proyecto: la “sobreinterpretación”. Los programas intencionales presentan una estructura alegórica al construir dos niveles de significación en los que el primero expresa un sentido literal aparente, el cual se hace transparente para señalar hacia el segundo nivel. ${ }^{7}$ La diferencia (y el peligro), sin embargo, es el intento de congelación

\footnotetext{
${ }^{7}$ Se toma como guía el concepto de alegoría presentado por Jonathan Culler en Flaubert. The Uses of Uncertainty: "Allegory is that mode which recognizes the impossibility of fusing the empirical
} 
del segundo significado. Los programas son sólo un simulacro bajo el cual hay un mensaje preconstruido el cual apunta hacia un receptor y un sentido predeterminados. Pero la llamada de atención sobre la fachada hace del artificio algo demasiado explícito, fácilmente detectable por los televidentes. De esta forma se genera una paranoia interpretativa: todo significante es expresión de un sentido oculto; todo puede leerse en función de un significado único. El acceso, sin embargo, es imposible, excepto para quienes conocen el código. Los mismos secuestrados caen en el ejercicio detectivesco y empiezan a descubrir mensajes codificados hasta en las telenovelas situando las acciones, una vez más, al interior de una lógica narrativa en la cual cada elemento se explica en función de la totalidad.

La insistencia en el hecho de que hay algo oculto bajo la superficie del mensaje periodístico establece un paralelismo con la estructura ficcional que se oculta tras el proyecto reporteril. Dentro del universo que García Márquez elabora, la correspondencia constituye un emblema de la integración del relato popular y el periodismo; la unión de lo que pretende ser literal y de lo que se asume como metafórico; lo que "expresa” la realidad y lo que la "re-crea”. Pero, a la vez funciona en un nivel ético al proponer la disolución de las oposiciones en medio de las cuales se construye la historia. Todo es manifestación de lo mismo. No extraña, por lo tanto, la idea reiterada de que el mal es sólo una manifestación del bien. Ideológicamente nos hallamos ante una propuesta de unidad. A lo que parece conducir todo este planteamiento no es finalmente a tratar de determinar qué es lo bueno o lo malo, ni quién se encuentra situado de uno u otro lado. En su proyecto pedagógico, García Márquez efectúa una reflexión sobre las posibilidades que se le ofrecen a la literatura para trascender sus límites y actuar más definidamente en el contexto social. Las técnicas del reportaje rompen el círculo que se establece alrededor de una concepción del fenómeno literario como una unidad cerrada y autosuficiente (por eso la utilización del cuento folclórico) atada al pasado. El periodismo efectúa la conexión con el presente (o con una ilusión de presente), lo que instala la literatura en la red de prácticas sociales y la libera de un peligroso círculo semiótico.

Por otro lado, la reflexión ética revierte sobre el género periodístico al plantear el peligro de una identificación demasiado profunda con el discurso ideológico dominante. El secuestro de los periodistas, más que por un control de la información, es motivado por su importante posición en la cúpula del poder colombiano. La desaparición de la actitud crítica que tanto sorprende a Francisco Santos se integra a la pérdida de perspectiva de la función social del periodista y de la imagen que éstos han construido de sí mismos. En el mensaje que graba como prueba de su supervivencia, Santos elabora una figura sintomática de su autopercepción como figuras públicas: los periodistas secuestrados son la libertad de prensa secuestrada (68). Hacia la señalización del peligro de aceptar como válida esta metonimia es que la obra canaliza su insistencia en la idea de que los secuestros no fueron resultado de un intento de censura, sino motivados por el valor de los periodistas como objeto de cambio.

and the eternal and thus demystifies the symbolic relation by stressing the separateness of the two levels, the impossibility of their remaining linked in time, and the importance of protecting each level and the link between them by making it arbitrary. (226) 
Como conclusión podemos plantear que la incorporación de la estructura formularia del relato folclórico popular a Noticia de un secuestro, constituye una proclamación de confianza en la existencia de una lógica que cohesione y le confiera sentido a los dolorosos sucesos que constituyen el material narrativo de la obra. El entretejimiento de elementos explícitamente ficcionales en el interior de un proyecto con aspiraciones periodísticas, instaura un proceso de doble vía en el que se relativizan los principios que distinguen ambos discursos. El discurso periodístico deconstruye la fijeza, la actitud moralizante y la pretensión totalizadora que caracteriza el relato folclórico, mientras que éste pone en consideración reflexiones sobre la relatividad de la concepción de la temporalidad y la ingenuidad de la aspiración a la representación del presente que el periodismo proclama. El encuentro entre la literatura y el periodismo, persistentemente anunciado por el autor de Noticia de un secuestro, y explícito en la retórica de la obra, constituye una propuesta que confía en la integración de los dos géneros en un proyecto que les confiera dignidad ética a ambos. Una vez desechas las oposiciones conflictivas mediante el recurso a las correspondencias totalizadoras, una tenue esperanza se abre camino al finalizar la obra: el análisis de la descomposición social en la escritura constituye un paso más en el proceso de reconocimiento de la bondad original de un pueblo que ha sobrevivido valientemente los horrores de un holocausto interminable.

\section{Bibliografía}

Aarne, Antti y Thompson, Stith. Los tipos del cuento folklórico. Fernando Peñalosa, trad. Helsinki: Academia Scientiarum Fennia, 1995.

Barthes, Roland. "Introducción al análisis estructural del relato.” Análisis estructural del relato. Ronald Barthes y otros. 2 ed. Buenos Aires: Tiempo Contemporáneo, 1972. 9-43.

Beltrán, Rosa. “García Márquez: ‘Licencias y reticencias de un estilo’ (sobre Noticia de un secuestro). XX Congreso Nacional de Literatura, Lingüística y Semiótica: Cien Años de Soledad 30 años después. Santafé de Bogotá: Instituto Caro y Cuervo, 1998. 31-40.

Bonner, Gerald. St. Augustine of Hippo; Life and Controversies. Philadelphia: Westminster Press, 1963.

Bremond, Claude. "La lógica de los posibles narrativos”. Análisis estructural del relato. Ronald Barthes y otros. 2 ed. Buenos Aires: Tiempo Contemporáneo, 1972. 87109.

Cañón, Luis. “García Márquez: el reportaje es el periodismo”. El País (19 de marzo 1996). El País Online. Marzo 1996.

Carranza, María Mercedes. “Secuestro de una noticia.” Revista Semana 736 (1996): 5056.

Culler, Jonathan. Flaubert; the Uses of Uncertainty. Ithaca, NY: Cornell University Press, 1974.

García Márquez, Gabriel. Noticia de un secuestro. México: Taller, 1996.

Gillen, Paul. "Myths of the Unknown: Omens and Oracular Discourse”. Journal of Pragmatics 13 (1989): 407-25. 
González-Pérez, Aníbal. Journalism and the Development of Spanish American Narrative. Cambridge: Cambridge University Press, 1993.

Harpham, Geoffrey Galt. Getting it Right. Language, Literature, and Ethics. Chicago: The University of Chicago, 1992.

Man, Paul de. Allegories of Reading. New Haven: Yale University Press, 1979.

Paz, Octavio. Los hijos del limo. 4 ed. Barcelona: Seix Barral, 1993.

Pombo, Roberto. "En Colombia no hay secretos. García Márquez habla de su nuevo libro”. Repertorio Crítico sobre Gabriel García Márquez. Luis Fernando García Núñez, ed. Santafé de Bogotá: Instituto Caro y Cuervo, 1995. 453-60.

Propp, Vladimir. Morfología del cuento. María Lourdes Ortiz, trad. Madrid: Fundamentos, 1971.

Róheim, Géza. Fire in the Dragon. Alan Dundes, ed. Princeton: Princeton University Press, 1992.

Russel, Frederick H. “'Only Something Good Can Be Evil’: The Genesis of Augustine’s Secular Ambivalence”. Theological Studies 51 (1990): 698-716.

St. Augustine. The Free Choice of the Will. Robert P. Russell, trad. Washington: The Catholic University of America Press, 1968.

Tatar, María. Off with their heads! Fairy Tales and the Culture of Childhood. Princeton: Princeton University Press, 1992.

Vergara, Isabel. "Noticia de un secuestro: La historia como horror apocalíptico". $X X$ Congreso Nacional de Literatura, Lingüística y Semiótica: Cien Años de Soledad 30 años después. Santafé de Bogotá: Instituto Caro y Cuervo, 1998. 75-83.

Workman, Mark E. "Folklore and the Literature of Exile”. Folklore, Literature, and Cultural Theory. Cathy Lynn Preston, ed. Nueva York: Garland, 1995. 29-42. 